\title{
Enantioselective Hydrosilylation of Imines Catalyzed by Diamine-Zinc Complexes ${ }^{\dagger}$
}

\author{
Bu-Mahn Park, Xinhui Feng, and Jaesook Yun* \\ Department of Chemistry and Institute of Basic Science, Sungkyunkwan University, Suwon 440-746, Korea \\ EE-mail: jaesook@skku.edu \\ Received March 9, 2011, Accepted March 24, 2011
}

\begin{abstract}
The efficient asymmetric hydrosilylation of imines in the presence of polymethylhydrosiloxane has been investigated by screening chiral diamine-zinc complexes. A series of chiral diamine ligands were prepared from optically pure 1,2-diphenyl-1,2-ethanediamine and screened for effectiveness. $N$-Benzylic substituents were required for high enantioselectivity; ligands with bulky groups or extra coordinating groups such as $\mathrm{OH}$ and $\mathrm{S}$ lowered the catalytic activity. The level of asymmetric induction was usually in $>90 \%$ ee range for aromatic imine substrates. A linear correlation between the ee of the ligand and that of the product was observed, indicating the presence of a 1:1 ratio of ligand to metal coordination in the active catalytic complex.
\end{abstract}

Key Words : Amines, Enantioselectiviy, Hydrosilylation, Imines, Zinc

\section{Introduction}

Asymmetric reduction of prochiral imines provides an effective route to enantiomerically enriched secondary amines, which are widely present in natural products and pharmaceutical compounds. ${ }^{1}$ Asymmetric hydrosilylations employing safe and inexpensive hydrosilanes as stoichiometric reducing agents have attracted interest since its discovery and become one of the useful reduction methods. ${ }^{2}$ While a number of metal complexes of $\mathrm{Ti}^{3}{ }^{3} \mathrm{Rh},{ }^{4} \mathrm{Ru},{ }^{5} \mathrm{Cu}^{6}{ }^{6}$ and $\mathrm{Re}^{7}$ were employed for enantioselective hydrosilylation of prochiral imines, we reported recently the first highly enantioselective hydrosilylation of imines catalyzed by a chiral diamine-zinc catalyst. ${ }^{8}$

The zinc-catalyzed asymmetric hydrosilylation was first reported by Mimoun et al. for the reduction of ketones using polymethylhydrosiloxane (PMHS) as the reducing agent. ${ }^{9}$ Since this discovery, other related zinc-catalyzed systems were followed by several groups, focusing on the reduction of ketones. ${ }^{10}$ However, efficient asymmetric reductions of prochiral imines were not reported until our report. Previously, Carpentier et al. reported a few examples of imine reductions using diamine ligands, however, their system reduced imines with poor enantioselectivities affording nearly a racemic mixture in low yields. ${ }^{11}$ We reasoned that the nitrogen atom of amine products could interfere with the catalytic turnover and enantioselectivity by tightly coordinating to the zinc catalyst instead of the original chiral ligand, and showed that this problem could be solved by a judicious choice of chiral ligands and imine precursors such as phosphinylimines. ${ }^{8}$ In this report, which expands our initial study, we describe full details of our investigation on the zinc-catalyzed hydrosilylation of imines.

\section{Results and Discussion}

Catalytic Systems. In preliminary studies, we have shown

This paper is dedicated to Professor Eun Lee on the occasion of his honourable retirement. that the combination of $6 \mathrm{~mol} \% \mathrm{ZnEt}_{2}$ and $N, N^{\prime}$-dibenzyl-1,2diphenyl-1,2-ethanediamine $((R, R)$-L1) resulted in an efficient catalyst for highly enantioselective hydrosilylations of phosphinylimines in $\mathrm{THF} / \mathrm{MeOH}$ at room temperature. ${ }^{8}$ Using excess PMHS in a mixture of THF and methanol was more efficient than using monomeric silanes or PMHS in pure THF in terms of reactivity and enantioselectivity. The desired amine product of high ee $(98 \%$ ee) was isolated in good yield after hydrolytic workup.

Based on the observed acceleration effect of methanol, ${ }^{11,12}$ other protic additives were investigated for their effectiveness. Reactions were carried out by using THF solvent containing $20 \%$ of alcohol $(\mathrm{ROH})$ by volume and the results are summarized in Table 1. Good conversions were obtained in all cases regardless of the bulkiness and acidity of alcohol, but the enantioselectivity greatly decreased as the bulkiness of the alcohol increased; isopropanol $\left(2^{\circ}\right)$ gave $90 \%$ ee and $t$ -

Table 1. Asymmetric hydrosilylations of $N$-diphenylphosphinylimine (1a) using various alcohol additives

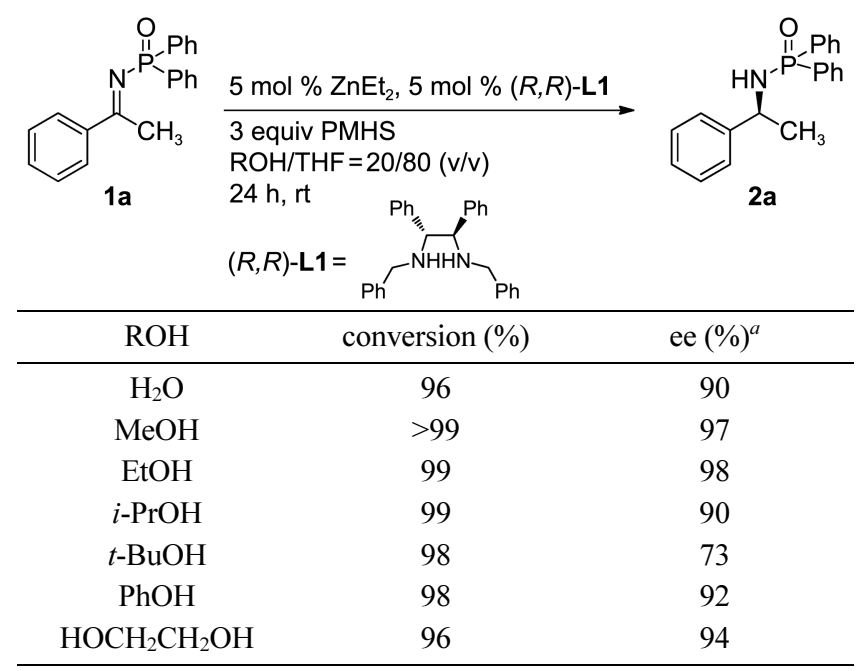

${ }^{a}$ Determined by chiral HPLC. 

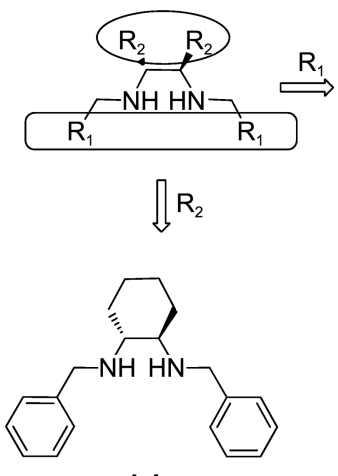

L4

$99 \%$ conv $(5 \%$ ee $)$
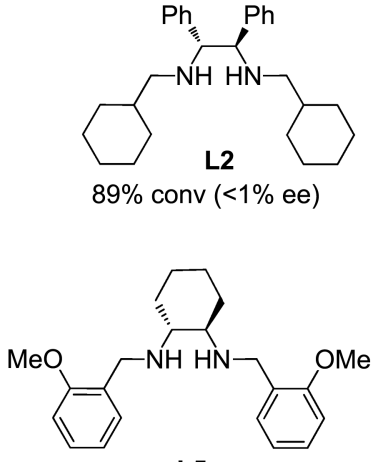

L5

$97 \%$ conv $(<1 \%$ ee $)$

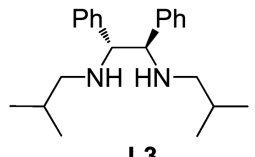

L3

$96 \%$ conv $(<1 \%$ ee $)$

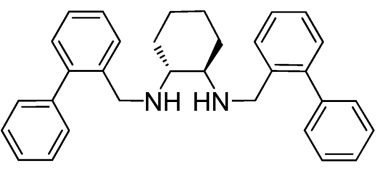

L6

$92 \%$ conv $(<2 \%$ ee $)$

Scheme 1. Modified diamine ligands which showed poor enantioselectivity.

butanol $\left(3^{\circ}\right)$ gave only $73 \%$ ee. Consequently, primary alcohols such as $\mathrm{MeOH}$ and $\mathrm{EtOH}$ were preferable additives and $\mathrm{MeOH}$ was finally chosen due to its easy removal after reaction.

Effect of Ligands on Enantioselectivity. Since $\mathrm{ZnEt}_{2}$ complexed by the diamine ligand L1 showed catalytic activity for reduction, a series of chiral diamines having an ethylenediamine backbone were prepared and tested to investigate the stereodiscriminating properties of each catalytic system (Scheme 1). Surprisingly, both the substituent $\left(\mathrm{R}_{1}\right)$ on the nitrogen and the substituent $\left(\mathrm{R}_{2}\right)$ on the alkyl backbone had a huge impact on the enantioselectivity. When the nitrogen substituents do not contain a phenyl group as in $\mathbf{L 2}$ and $\mathbf{L 3}$ or the backbone is cyclohexyldiamine (L4-L6), the reduction of phosphinylimine (1a) afforded nearly a racemic product.

The reduction of a phosphinylimine affords an amine product, which can possibly coordinate the zinc catalyst as the ligand. To probe the effect of the amine product (2a) on the reactivity and enantioselectivity, we carried out a reduction reaction of $\mathbf{1 a}$ with $10 \mathrm{~mol} \%$ of $(S)-\mathbf{2 a}(98 \%$ ee) as the ligand in the absence of the diamine ligand (L1) otherwise under the same conditions (eq. 1). Surprisingly, this reaction proceeded with $93 \%$ conversion in $12 \mathrm{~h}$ and afforded the desired product in $14 \%$ ee. The results indicate that an inadvertent shortage of more tightly-coordinating bidentate diamine ligands relative to the zinc catalyst would possibly decrease the enantioselectivity via less selective background reactions. Indeed, employing a slight excess of $\mathbf{L} \mathbf{1}$ to zinc increased enantioselectivity and afforded the amine product in $99 \%$ ee (Scheme 2, see also Table 2). Therefore, this ratio of ligand to the metal was kept for further study.

Given that enantioselectivity was greatly affected by subtle changes in the diamine ligands, several ligands possessing various $N$-benzylic substituents were prepared from $(S, S)$ -

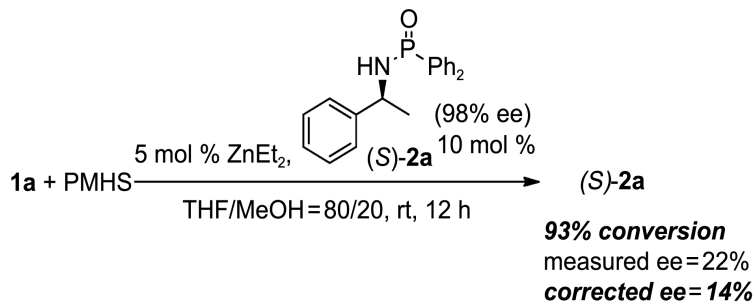

dpen (dpen =1,2-diphenyl-1,2-ethanediamine) and screened for effectiveness in the hydrosilylation reactions of phosphinylimine 1a (Scheme 2). Replacement of the phenyl moiety by aryl groups possessing an ortho substituent (L7-L9) or by 1naphthyl $(\mathbf{L 1 4})^{13}$ did not significantly affect the enantioselectivity. However, ligand L10 having coordinating hydroxyl groups completely blocked the reactivity. 2-Thienyl substituted ligand L11 gave also poor conversion and moderate enantioselectivity. Bulky mesityl-substituted L12 and tetrabenzyl substituted diamine ligand L13 resulted in partial conversions and poor enantioselectivities as well. Therefore, it seems that diamine ligands with an aryl group of moderate size and no strongly coordinating additional groups on each nitrogen atom are essential for high enantioselectivity.

Next, asymmetric reductions of several phosphinylimines were examined with promising diamine ligands (L1, L7 and L8) under the new reaction conditions employing a slight excess of ligand to zinc (Table 2). A moderate increase in enantiomeric excess values was observed with substrates 1c and 1d, as a result from the reduced background reaction (entries 3, 4, 6 and 7). Generally, the $\mathbf{L} 7$ and $\mathbf{L 8}$ ligands were as effective as L1 in terms of enantioselectivity. Arylalkylimines (1b, 1c and 1e) were reduced with excellent enantioselectivities over $90 \%$ ee, but arylimine 1d having an isopropyl group was less selective. Dialkylimine $\mathbf{1 f}$ was reduced with a good level of enantioselectivity as well (entries 11 and 12). A tosylimine derivative, $\mathbf{1 g}$ was an appropriate substrate for the current catalytic reduction system, and particularly, the modified ligand (L8) was highly efficient for the reduction of the substrate (entry 14).

Mechanistic Consideration. For insight into the aggregation state of the active catalyst under theses reduction conditions, experiments using the ligand $\mathbf{L} \mathbf{1}$ of varying ee under our original conditions ( $5 \mathrm{~mol} \% \mathrm{ZnEt}_{2}, 5 \mathrm{~mol} \% \mathbf{L 1}$, PMHS,

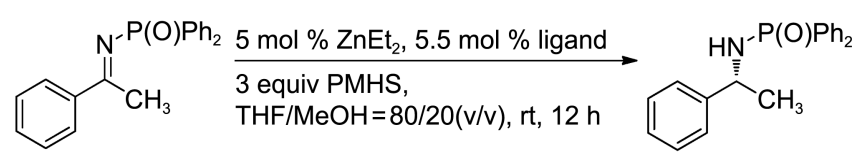

Scheme 2. Various diamine ligands derived from $(S, S)$-dpen screened for effectiveness. 
<smiles>c1ccc(CNC(c2ccccc2)[C@H](NCc2ccccc2)c2ccccc2)cc1</smiles>

L1

$86 \%$ yield, $99 \%$ ee $84 \%$ yield, $96 \%$ ee $(4.5 \mathrm{~mol} \%)$

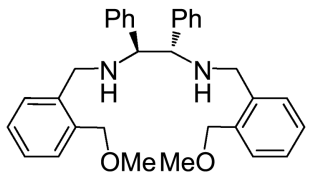

L9

$67 \%$ yield, $98 \%$ ee

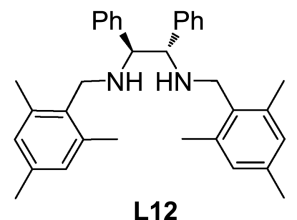

$78 \%$ yield, $13 \%$ ee

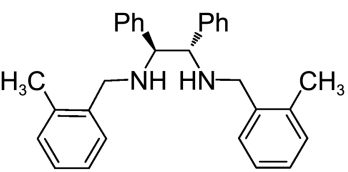

L7

$81 \%$ yield, $95 \%$ ee

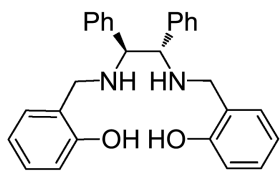

10

no reaction<smiles>c1ccc(CN(Cc2ccccc2)C(c2ccccc2)c2ccccc2)cc1</smiles>

L13

$62 \%$ yield, $1 \%$ ee

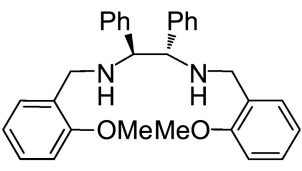

L8

$82 \%$ yield, $97 \%$ ee

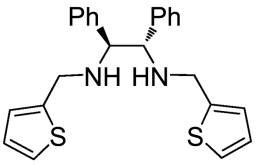

L11

$40 \%$ yield, $64 \%$ ee

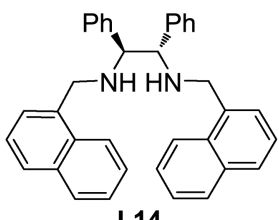

$88 \%$ yield, $96 \%$ ee
Table 2. Enantioselective hydrosilylation of activated imines

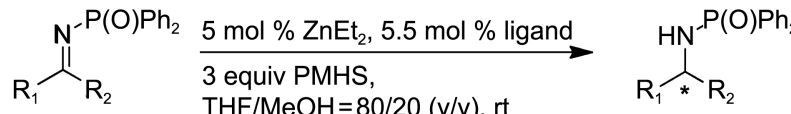

$$
\begin{aligned}
& 1 \mathrm{THF} / \mathrm{MeOH}=80 / 20(\mathrm{v} / \mathrm{v}) \text {, rt } 2
\end{aligned}
$$

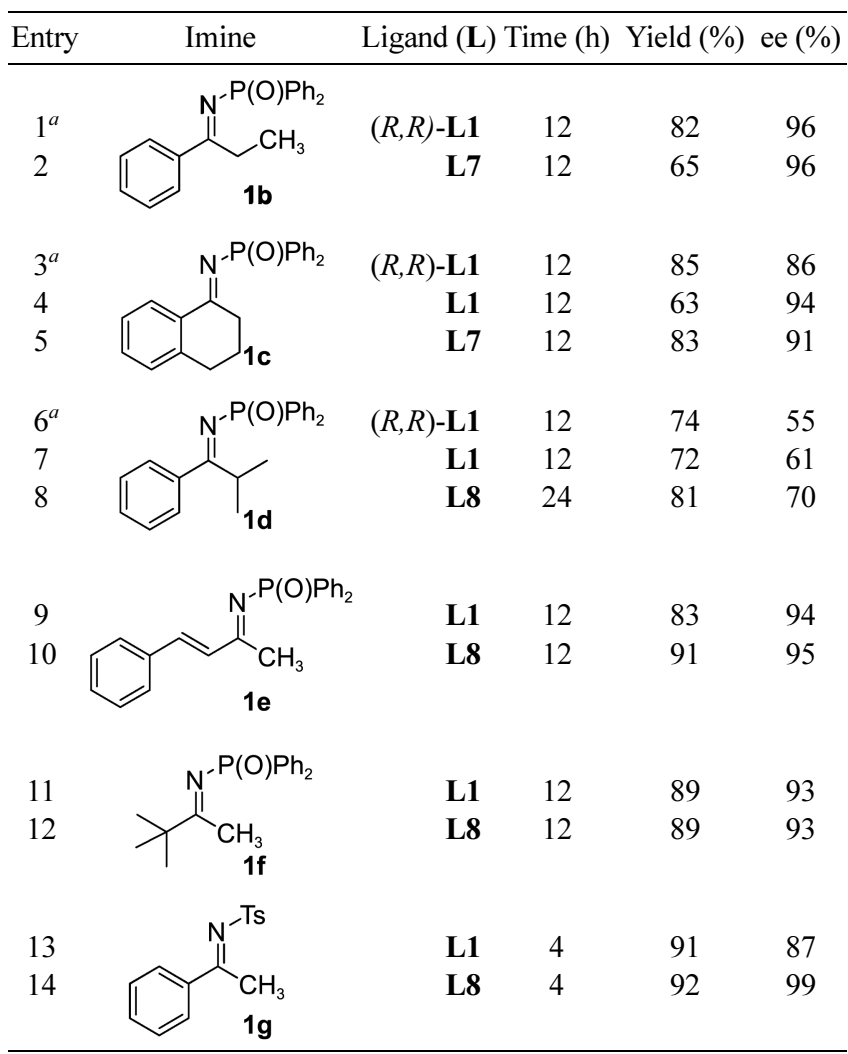

$a_{5} \mathrm{~mol} \%$ of ligand was used.

rt in THF/MeOH) were carried out. As shown in Figure 1, a linear correlation between the ee of the ligand and that of the product was observed, indicating that a 1:1 ratio of ligand to

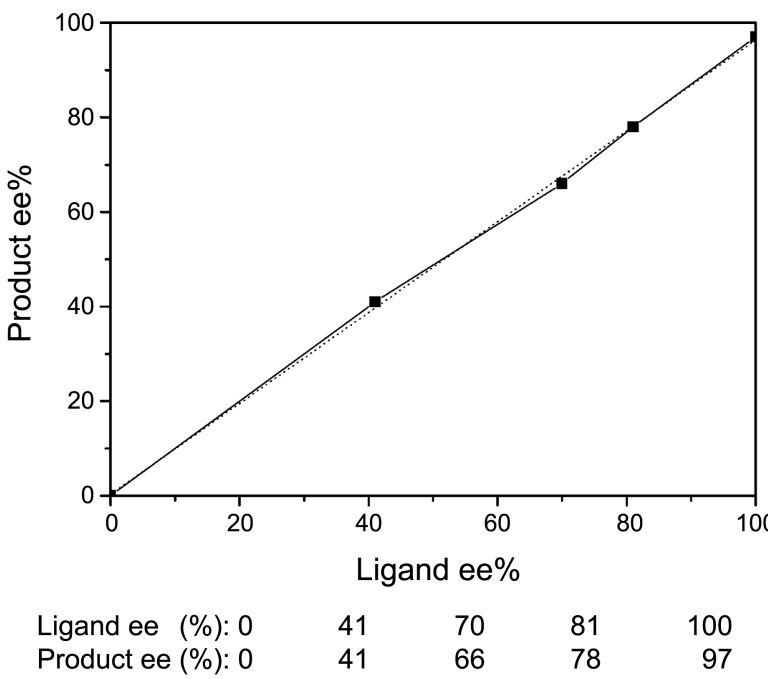

Figure 1. Asymmetric reduction of $\mathbf{1 a}$ using $\mathbf{L 1}$ of varying ee; plot of ee of product amine (2a) as a function of ee of the ligand.

metal is present in the catalytic complex (ML). The absence of nonlinear effects ${ }^{14}$ in these reductions indicates that a single diamine ligand is involved in the active catalyst and that no associations of the chiral ligands occur.

A possible catalytic cycle for the zinc-catalyzed hydrosilylation of imines is proposed in Scheme 3. Since the inclusion of alcohol additives and types of the alcohol affected the enantioselectivity (Table 1 and 2), we propose that an alkoxide bound zinc species $(\mathbf{I})^{11,15}$ is the key intermediate in the catalytic cycle. Asymmetric reduction with imine occurs, resulting in formation of new zinc intermediate (II), which subsequently undergoes reaction with alcohol to yield an amine product and a zinc dialkoxide intermediate. This intermediate reacts with hydrosilane to regenerate the active zinc species. 


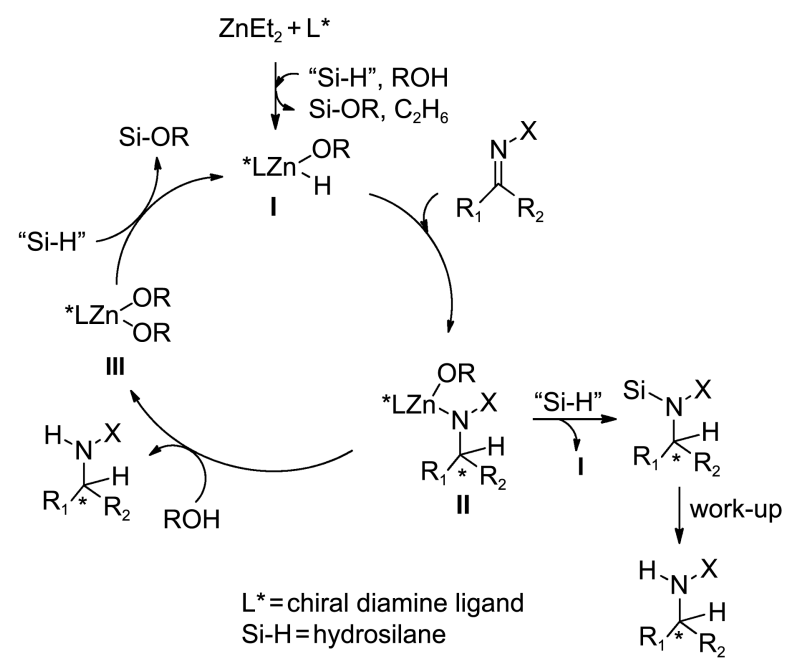

Scheme 3. A possible reaction pathway.

\section{Conclusions}

We have described an efficient method for the enantioselective hydrosilylation of prochiral imines catalyzed by zinc-chiral diamine complexes. In light of a strong zinc-nitrogen ( $\mathrm{Zn}-\mathrm{N})$ bond, ${ }^{16}$ use of activated imines such as phosphinylimines and tosylimines was important for reactivity and enantioselectivity under the catalytic system. In general, chiral secondary diamine ligands derived from optically pure 1,2-diphenyl1,2-ethanediamine were highly effective, but simple alkyl substituted (no aryl) or dibenzylated ligands on the nitrogen afforded products of very low ee's $(<5 \%$ ee). The ligand having coordinating phenoxy group was not effective for the reaction either. Based on the study of the effect of alcoholic additives on the enantioselectivity and that of linear effect, an alkoxyzinc-hydride species was proposed as the key intermediate in the catalytic reaction. High enantioselectivities were obtained in typical reductions with optimized diamine ligands. In particular, the ortho-methoxy substituted ligand (L8) was proved highly efficient in the asymmetric reduction of tosylimine derivatives. Further work to examine applications and mechanism of the catalyst system is underway.

\section{Experimental Section}

General Procedure for the Enantioselective Hydrosilylation of Imines. To a solution of L1 $(9.5 \mathrm{mg}, 0.0242 \mathrm{mmol})$ in anhydrous THF $(0.4 \mathrm{~mL})$ was added $\mathrm{ZnEt}_{2}(0.02 \mathrm{~mL}, 1.1 \mathrm{M}$ solution in toluene, $0.022 \mathrm{mmol})$ under an atmosphere of nitrogen in a Schlenk tube. The reaction mixture was stirred for $10 \mathrm{~min}$. Imine substrate $(0.44 \mathrm{mmol})$ in THF $(0.4 \mathrm{~mL})$, PMHS (0.08 mL, $1.32 \mathrm{mmol})$ and anhydrous $\mathrm{MeOH}(0.2$ $\mathrm{mL})$ were sequentially added. The resulting solution was stirred for $12 \mathrm{~h}$ at room temperature and the reaction was monitored by TLC. After completion of the reaction, brine was added to the mixture and the aqueous layer was extracted with EtOAc $(3 \times 20 \mathrm{~mL})$. The combined organic layers were dried over $\mathrm{Na}_{2} \mathrm{SO}_{4}$, filtered, and concentrated under vacuum. The desired amine product (2) was purified by flash chromatography.

$\mathbf{2 a}^{8}$ : ${ }^{1} \mathrm{H} \mathrm{NMR}\left(400 \mathrm{MHz}, \mathrm{CDCl}_{3}\right) \delta$ 7.91-7.86 (m, 2H), 7.83$7.78(\mathrm{~m}, 2 \mathrm{H}), 7.49-7.20(\mathrm{~m}, 11 \mathrm{H}), 4.40-4.35(\mathrm{~m}, 1 \mathrm{H}), 3.20-3.16$ $(\mathrm{m}, 1 \mathrm{H}), 1.57(\mathrm{~d}, J=6.6 \mathrm{~Hz}, 3 \mathrm{H}) ;{ }^{13} \mathrm{C}\left\{{ }^{1} \mathrm{H}\right\} \mathrm{NMR}(100 \mathrm{MHz}$, $\left.\mathrm{CDCl}_{3}\right) \delta 145.2,133.9-132.6(\mathrm{~m}), 132.1-131.6(\mathrm{~m}), 128.7-$ $128.5(\mathrm{~m}), 127.3,126.1,51.4,26.4(\mathrm{~d}, J=3.1 \mathrm{~Hz}) ; 99 \%$ ee by HPLC (Chiral OD-H column, 2-propanol:hexanes = 10:90 (0.5 $\mathrm{ml} / \mathrm{min}$ ), minor isomer $11.0 \mathrm{~min}$, major isomer $13.8 \mathrm{~min}$ ).

$2 \mathbf{g}^{17}$ (with L8): ${ }^{1} \mathrm{H}$ NMR (400 MHz, $\left.\mathrm{CDCl}_{3}\right) \delta 7.62$ (d, $J=$ 8.1 Hz, 2H), 7.09-7.21 (m, 7H), 4.77 (d, $J=6.7 \mathrm{~Hz}, 1 \mathrm{H}), 4.44-$ $4.48(\mathrm{~m}, 1 \mathrm{H}), 2.39(\mathrm{~s}, 3 \mathrm{H}), 1.43(\mathrm{~d}, J=6.8 \mathrm{~Hz}, 3 \mathrm{H}) ; 99 \%$ ee by HPLC (Chiral AD-H column, 2-propanol:hexanes = 10:90 (0.5 $\mathrm{ml} / \mathrm{min}$ ), major isomer $20.9 \mathrm{~min}$, minor isomer $23.6 \mathrm{~min}$ ).

Acknowledgments. This research was supported by Basic Science Research Program through the National Research Foundation of Korea (NRF-20090085824).

\section{References}

1. (a) Nishiyama, H.; Itoh, K. In Catalytic Asymmetric Synthesis, 2nd ed.; Ojima, I., Ed.; Wiley-VCH: New York, 2000; Chapter 2. (b) Nishiyama, H. In Comprehensive Asymmetric Catalysis; Jacobson, E. N., Pfaltz, A., Yamamoto, H., Eds.; Springer: Berlin, 1999; Chapter 6.3.

2. (a) Yamamoto, K.; Uramoto, Y.; Kumada, M. J. Organomet. Chem. 1971, 31, C9. (b) Ojima, I.; Nihonyanagi, M.; Nagai, Y. J. Chem. Soc. Chem. Commun. 1972, 938. (c) Dumont, W.; Poulin, J.-C.; Dang, T.-P.; Kagan, H. B. J. Am. Chem. Soc. 1973, 95, 8295. (d) Brunner, H.; Riepl, G. Angew. Chem. Int. Ed. Engl. 1982, 21, 377. (e) Arena, C. G. Mini-Rev. Org. Chem. 2009, 6, 159.

3. (a) Verdaguer, X.; Lange, U. E. W.; Reding, M. T.; Buchwald, S. L. J. Am. Chem. Soc. 1996, 118, 6784. (b) Gruber-Woelfler, H.; Khinast, J. G. Organometallics 2009, 28, 2546.

4. Becker, R.; Brunner, H.; Mahboobi, S.; Wiegrebe, W. Angew. Chem. Int. Ed. Engl. 1985, 24, 995.

5. Nishibayashi, Y.; Takei, I.; Uemura, S.; Hidai, M. Organometallics 1998, 17, 3420 .

6. Lipshutz, B. H.; Shimizu, H. Angew. Chem. Int. Ed. 2004, 43, 2228 .

7. (a) Nolin, K. A.; Ahn, R. W.; Toste, F. D. J. Am. Chem. Soc. 2005, 127, 12462. (b) Nolin, K. A.; Ahn, R. W.; Kobayashi, Y.; KennedySmith, J. J.; Toste, F. D. Chem. Eur. J. 2010, 16, 9555.

8. Park, B.-M.; Mun, S.; Yun, J. Adv. Synth. Catal. 2006, 348, 1029.

9. (a) Mimoun, H. J. Org. Chem. 1999, 64, 2582. (b) Mimoun, H.; Laumer, J. Y.; Giannini, L.; Scopelliti, R.; Floriani, C. J. Am. Chem. Soc. 1999, 121, 6158.

10. (a) Bette, V.; Mortreux, A.; Lehmann, C. W.; Carpentier, J.-F. Chem. Commun. 2003, 332. (b) Bandini, M.; Melucci, M.; Piccinelli, F.; Sinisi, R.; Tommasi, S.; Umani-Ronchi, A. Chem. Commun. 2007, 4519. (c) Inagaki, T.; Yamada, Y.; Phong, L. T.; Furuta, A.; Ito, J.-i.; Nishiyama, H. Synlett 2009, 253. (d) Santacruz, E.; Huelgas, G.; Angulo, S. K.; Mastranzo, V. M.; Hernández-Ortega, S.; Aviña, J. A.; Juaristi, E.; de Parrodi, C. A.; Walsh, P. J. Tetrahedron: Asymmetry 2009, 20, 2788. (e) Gajewy, J.; Kwit, M.; Gawroński, J. Adv. Synth. Catal. 2009, 351, 1055.

11. Bette, V.; Mortreux, A.; Savoia, D.; Carpentier, J.-F. Adv. Synth. Catal. 2005, 347, 289.

12. For more examples in other metal-catalyzed reactions, see: (a) Yun, J.; Buchwald, S. L. J. Am. Chem. Soc. 1999, 121, 5640. (b) Hughes, G.; Kimura, M.; Buchwald, S. L. J. Am. Chem. Soc. 2003, 125, 11253. (c) Mun, S.; Lee, J.-E.; Yun, J. Org. Lett. 2006, 8, 4887. 
13. A similar 2-naphthyl-substituted ligand afforded the product in $96 \%$ ee.

14. (a) Girard, C.; Kagan, H. B. Angew. Chem. Int. Ed. 1998, 37, 2922. (b) Guillaneux, D.; Zhao, S.-H.; Samuel, O.; Rainford, D.; Kagan, H. B. J. Am. Chem. Soc. 1994, 116, 9430.

15. This model also explains the inactivity of $\mathbf{L 1 0}$, the $\mathrm{OH}$ groups of which block the active site of the catalyst.
16. For example, $D(\mathrm{Zn}-\mathrm{N})$ in $\mathrm{Zn}\left[\mathrm{N}(\mathrm{TMS})_{2}\right]_{2}=209 \mathrm{~kJ} / \mathrm{mol}, D(\mathrm{Zn}-\mathrm{C})$ in $\mathrm{Zn}\left[\mathrm{CH}_{2} \mathrm{CMe}_{3}\right]_{2}=157 \mathrm{~kJ} / \mathrm{mol}$, see: Gümrükçüoglü, I. E.; Jeffery, J.; Lappert, M. F.; Pedley, J. B.; Rai, A. K. J. Organomet. Chem. 1988, 341, 53.

17. Yang, Q.; Shang, G.; Gao, W.; Deng, J.; Zhang, X. Angew. Chem. Int. Ed. 2006, $45,3832$. 